\title{
The bridge dynamic properties monitoring
}

\author{
Jozef Melcer ${ }^{1, *}$, Daniela Kuchárová1 ${ }^{1}$, and Gabriela Lajčáková ${ }^{1}$ \\ ${ }^{1}$ University of Zilina, Faculty of Civil Engineering, Slovak Republic
}

\begin{abstract}
The SNP Bridge over the Danube in Bratislava represents an attractive steel cable-stayed bridge. Its length is $431.8 \mathrm{~m}$. The submitted paper describes the methodology of experimental testing and presents some results of the loading test. During this test it was observed that the dilatation unit on the right water side shows some failure. Due to this failure the dilatation unit acts as a generator of vibration of the end bridge span. On the basis of experimental measurements this failure was detected and the dilatation unit was renovated.
\end{abstract}

\section{Introduction}

The SNP Bridge over the Danube in Bratislava represents an attractive steel cablestayed bridge. It was opened in the year 1972. It serves for taking over the express highway from Bratislava to Vienna. All the dynamic characteristics are periodically monitored. A reconstruction was carried out during summer days in 2004. It was the reason for control of dynamic characteristics of the bridge and for carrying out so call studying loading test of the bridge. The submitted paper describes the methodology of experimental measurements and presents some results of this loading test mainly values of dynamic coefficients and values of natural frequencies.

\section{Short description of the bridge construction}

The SNP Bridge is the steel cable-stayed bridge crossing the Danube in Bratislava. Its length is $431.8 \mathrm{~m}$. The length of the middle span over the Danube is $303.0 \mathrm{~m}$ and the lengths of the end spans are $74.8 \mathrm{~m}$ and $54.0 \mathrm{~m}$. Bearing cables are lead over sloping pylon $77 \mathrm{~m}$ tall. The cross section is box with two cells and two consoles on a level of upper and lower slabs. Vertical beams and horizontal slabs are stiffened by cross and longitudinal braces. Sloped diagonals fix the space stability. Width of bridge deck is $2 \times 10.5=21.0 \mathrm{~m}$. Bearing cables are anchored in the middle of cross section so the bridge is predisposed to rotational movements. Static scheme in longitudinal direction is shown in the Fig. 1.

\footnotetext{
*Corresponding author: jozef.melcer@fstav.uniza.sk
} 


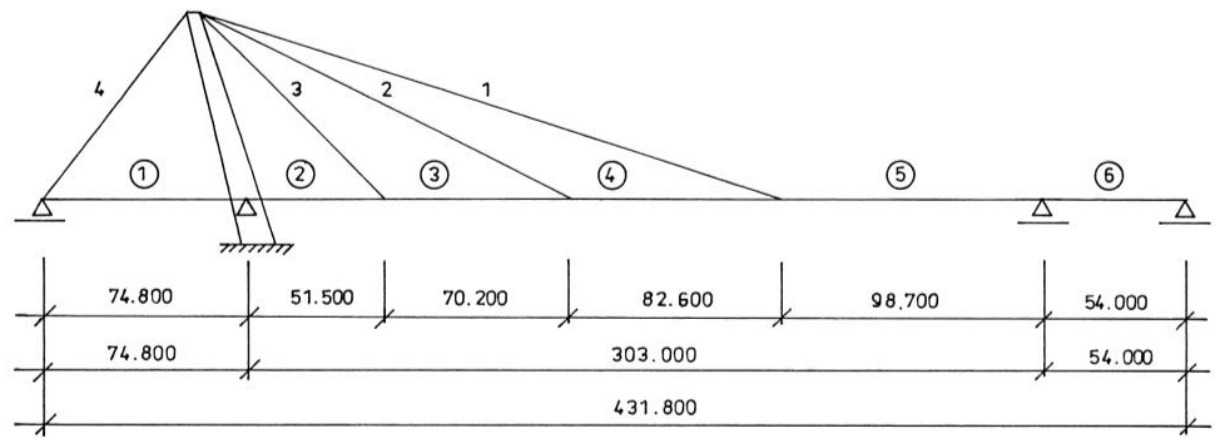

Fig. 1. Static scheme of the bridge.

\section{Applied experimental equipment}

The main goals of the measurement during studying loading test were following of vertical displacements and strains in selected points of the structure and vertical and horizontal accelerations in selected points [1]. For the registration of those physical quantities following equipment was used: inductive sensors Bosh, tensometers Kistler 9232A and amplifiers Kistler 5011, accelerometers Brüer-Kjaer BK 8306 and amplifiers BK 2635, Fig. 2.

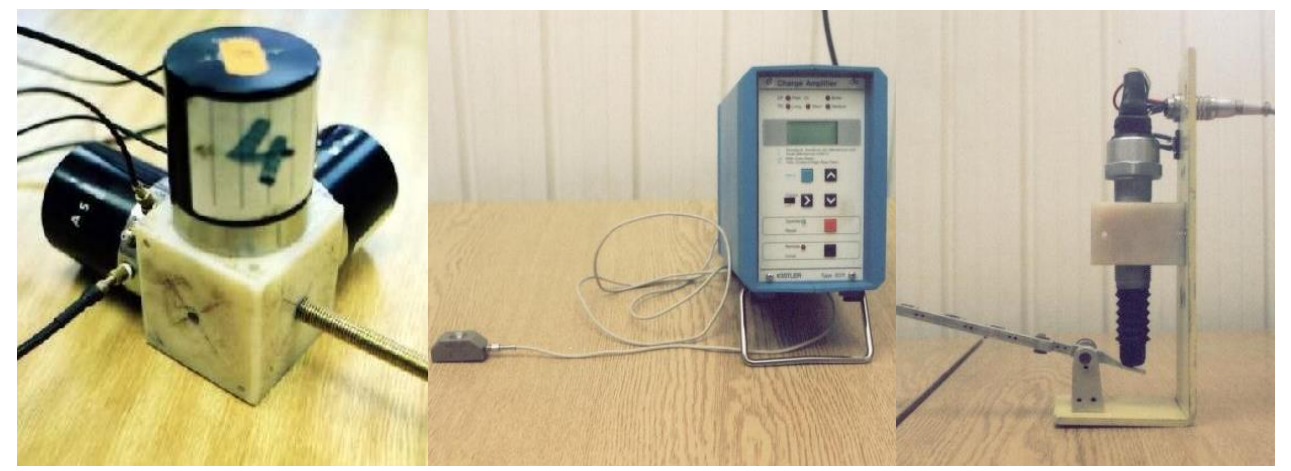

Fig. 2. Sensors Bosh, Kistler and Brüer-Kjaer.

Signals from the sensors were leaded by means of coaxial cables to measuring central. Measuring line consists from these components: sensor, amplifier, signal cable, AD interface, operating computer. All the analyses were carry out by numerical way through the program system DISYS.

\section{Results of experimental measurements}

In this paper only the values of dynamic coefficients $\delta_{\text {obs }}$ in the $1^{\text {st }}$ span from the side of Petržalka are presented. Dynamic coefficient is defined as $\delta_{o b s}=S_{\max } / S_{m}$ where $\mathrm{S}_{\max }$ is maximal dynamic deflection and $S_{\mathrm{m}}$ is maximal static deflection [2]. Dependence $\delta_{\mathrm{obs}}$ versus speed of vehicle motion for smooth runs of vehicle is presented in the Fig. 3. 


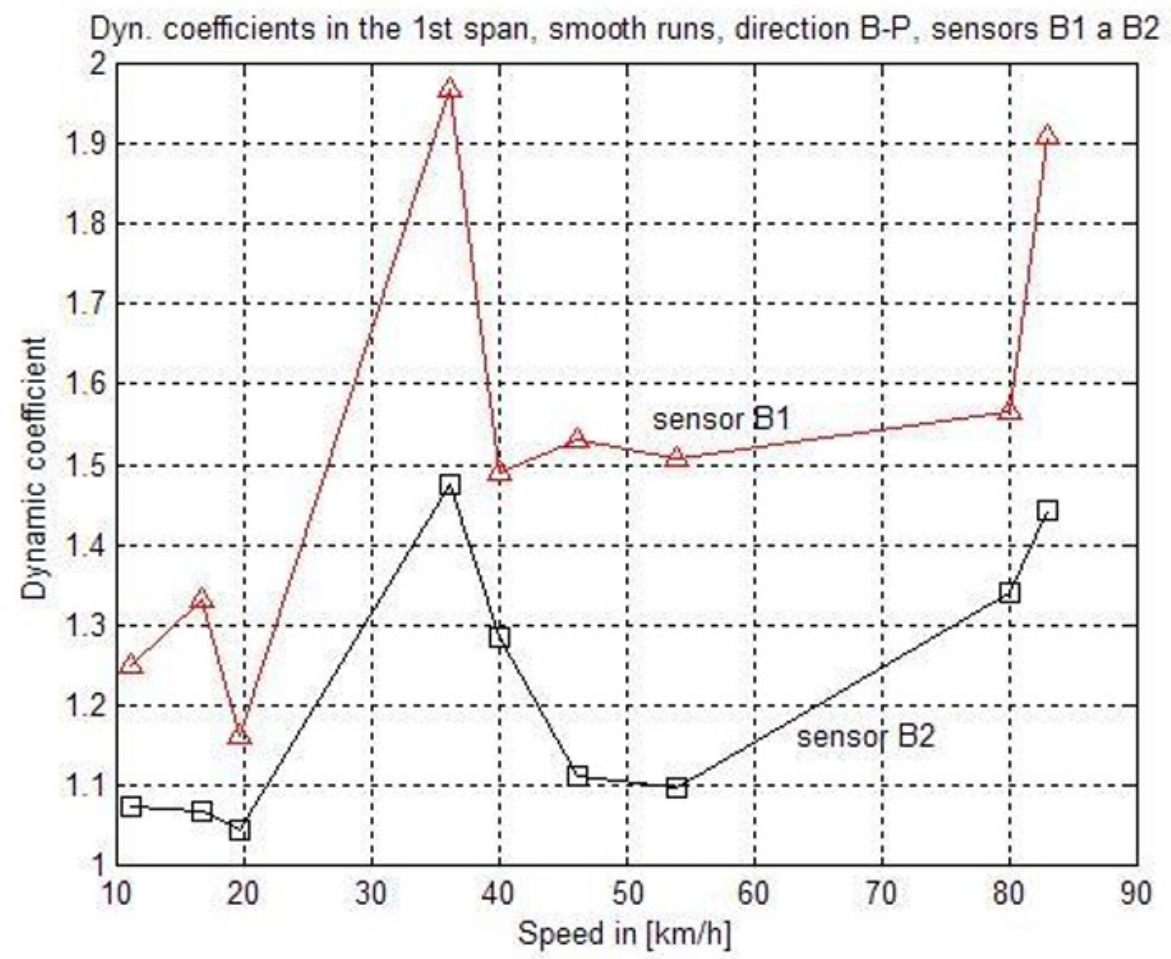

Fig. 3. Dynamic coefficient versus speed of vehicle motion.

In the Fig. 4 and Fig. 5 the typical time process of vibration as a sample is presented.

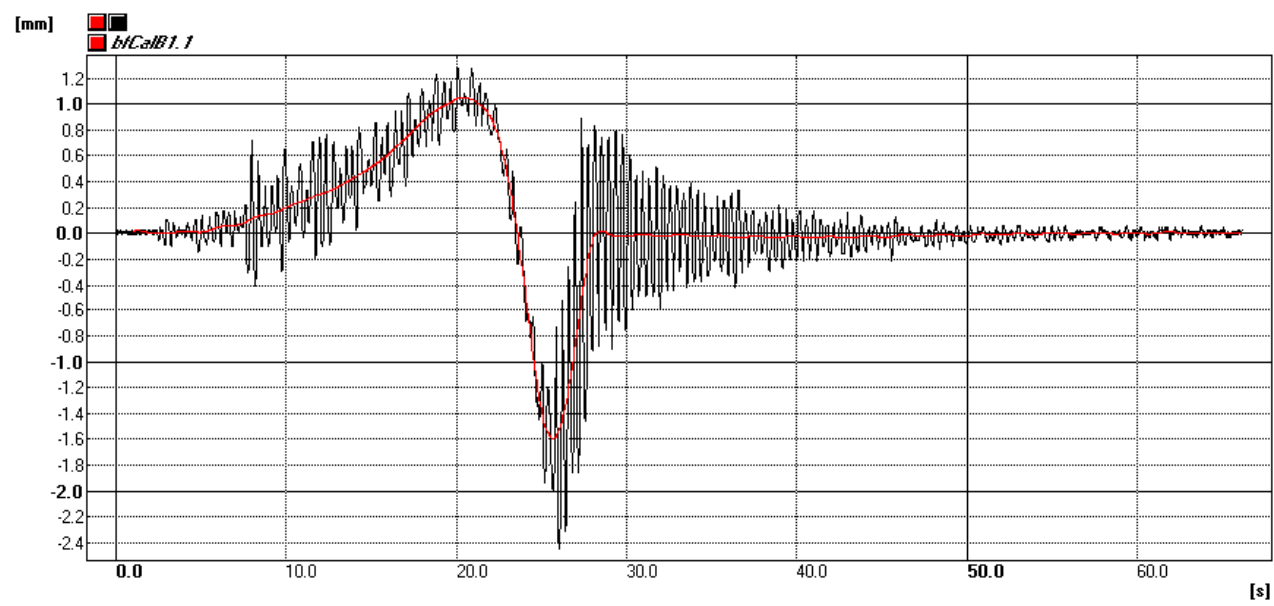

Fig. 4. Smooth run No.7, direction B $-\mathrm{P}$, sensor B1, $\delta_{\mathrm{obs}}=1.5322$. 


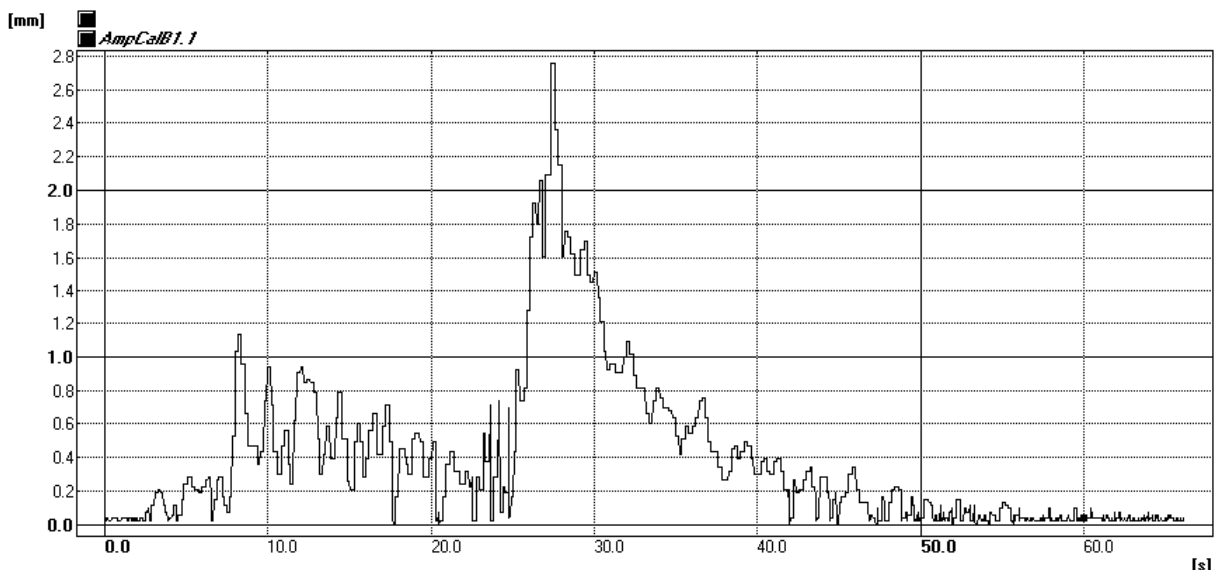

Fig. 5. Two-amplitudes of vibration, smooth run No.7, direction B - P, sensor B1.

It is seen from the above figures that the maximal dynamical deflection appears at the moment of passing vehicle over dilatation unit. The dilatation unit acts as a generator of vibration. The bridge construction evocates its tendency to rotational movements. It is seen very well from the comparison of time processes of vibration from the sensors B1 and B2 situated on left and right side of the structure in the Fig. 6.

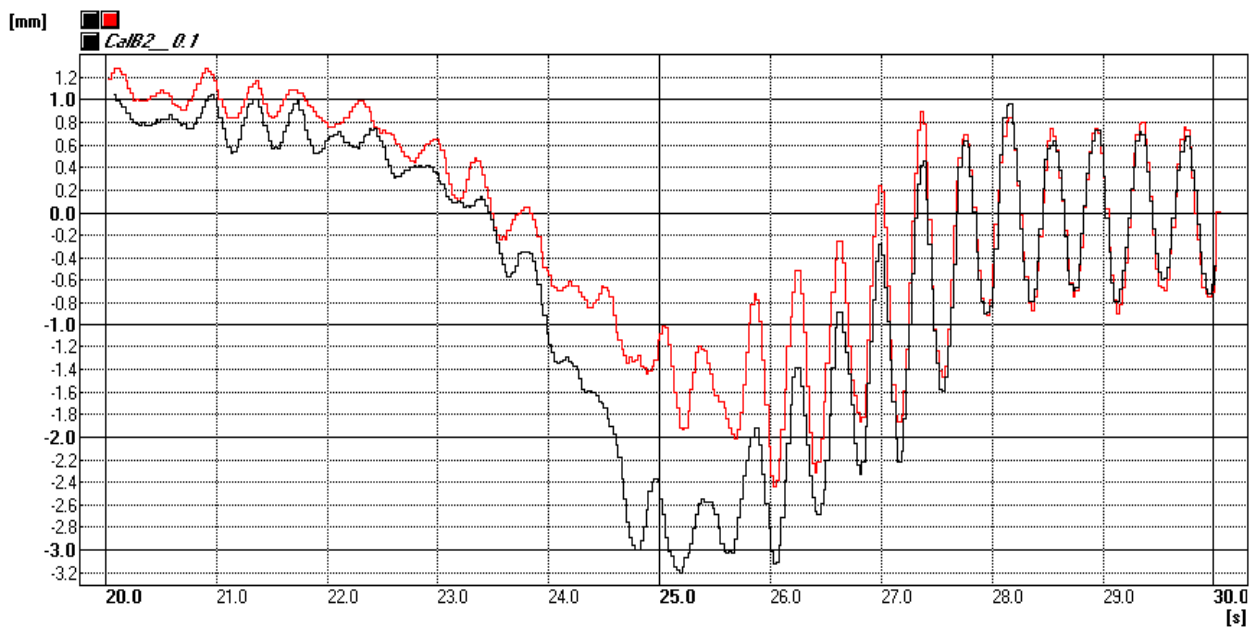

Fig. 6. Comparison of time processes of vibration from the sensors B1 and B2, smooth run No.7, direction B-P, sensor B1-up, sensor B2-down.

From the dynamical point of view the natural frequencies represent the very important numerical characteristics defining the dynamical individuality of the bridge.

The changes of these characteristics are connected with the changes of mechanical properties the bridge and they can signalise possible defect of the structure. With respect to this fact the computational simulating model was created in the year 1999.

The model was harmonized with the results of experimental measurements. These results serve as reference base for future experimental measurements. The calculated natural frequencies are introduced in the Tab. 1. 
Table 1. Calculated natural frequencies.

\begin{tabular}{|c|c|c|c|}
\hline $\mathbf{j}$ & $\mathbf{f}_{(\mathbf{j})}[\mathbf{H z}]$ & $\mathbf{j}$ & $\mathbf{f}_{(\mathbf{j})}[\mathbf{H z}]$ \\
\hline 1 & 0.2523 & 6 & 0.7942 \\
\hline 2 & 0.3124 & 7 & 1.4944 \\
\hline 3 & 0.4236 & 8 & 2.4757 \\
\hline 4 & 0.4728 & 9 & 3.5798 \\
\hline 5 & 0.5087 & 10 & 5.5642 \\
\hline
\end{tabular}

All the calculated natural frequencies were experimentally confirm by the results of experimental measurements as we can see from the power spectral densities of vibration on the Fig. 7-9. A little problematic is the frequency range from 0 to $1 \mathrm{~Hz}$. The frequencies in this frequency range are on the sensitivity boundary of used sensors. On the other hand it is also the problem too excite some natural modes of vibration only by passing the vehicles. The power spectral density on the Fig. 7 expressly confirm the 1 st natural frequency $f(1)=$ $0.25 \mathrm{~Hz}$ corresponding to the torsional vibration of the bridge. The peak corresponding to the 2 nd natural frequency $\mathrm{f}(2)=0.31 \mathrm{~Hz}$ is not so sharp because it is practically impossible to excite the 2 nd mode of natural vibration only by passing of one vehicle.

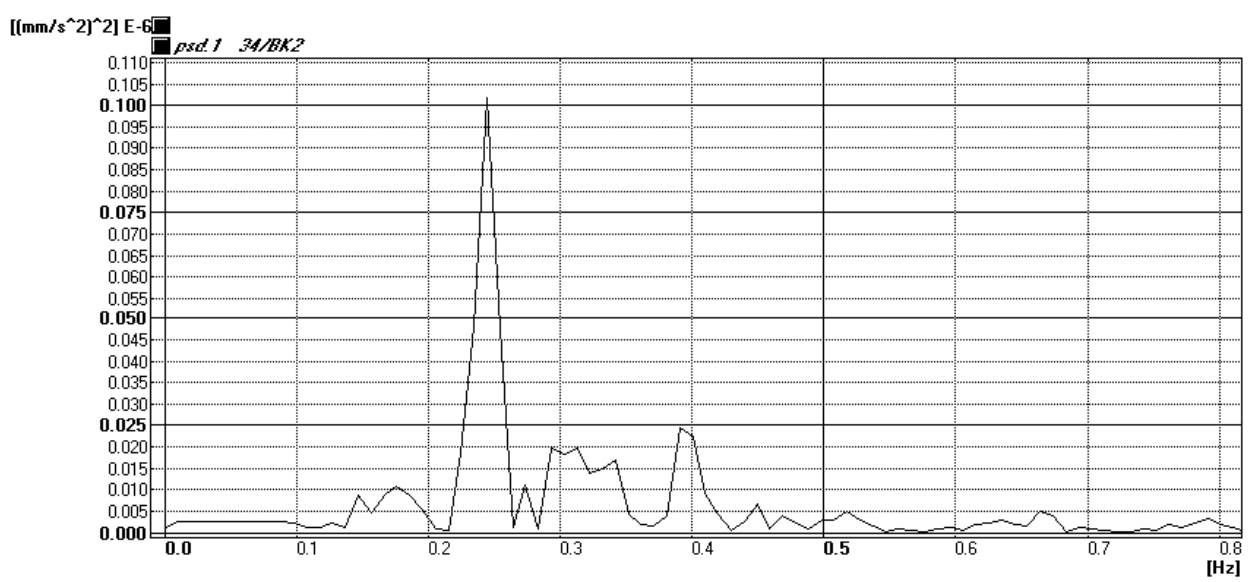

Fig. 7. The 1st sharp peak corresponding to the 1st natural frequency.

All the natural frequencies in the frequency range $0-1 \mathrm{~Hz}$ are clearly confirm by the power spectral density in the Fig. 8 .

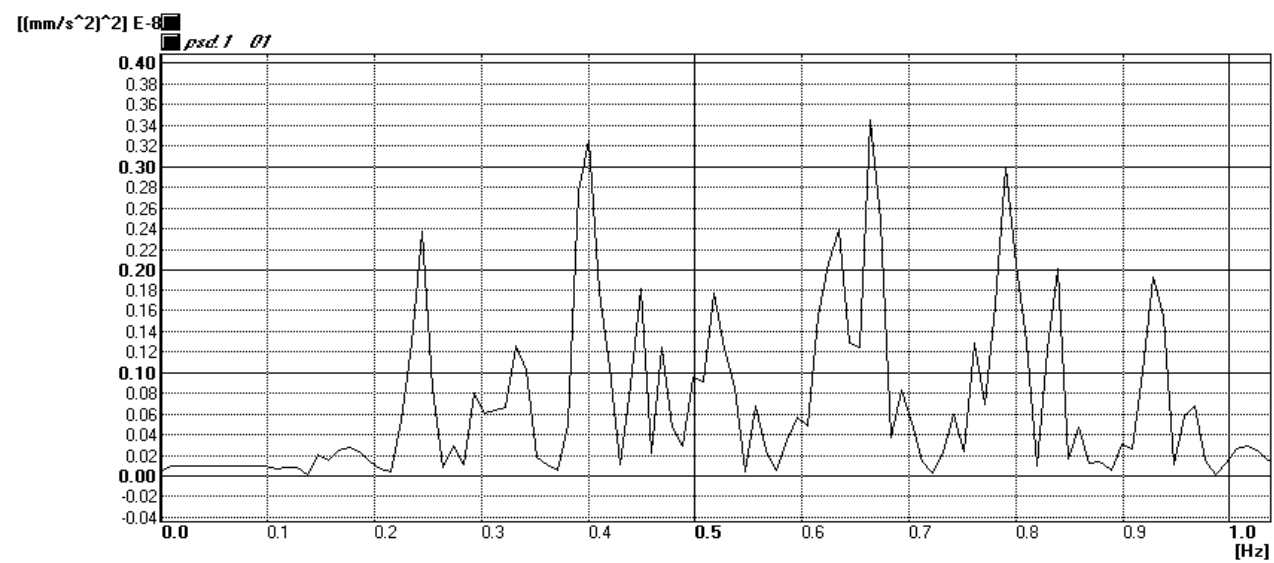

Fig. 8. The peaks in PSD correspond to the frequencies $0.25 ; 0.33 ; 0.40 ; 0.45 ; 0.47 ; 0.52 ; 0.63$; $0.66 ; 0.79 ; 0.84 ; 0.93 \mathrm{~Hz}$. 
In the Fig. 9 the peaks in power spectral density, corresponding the frequencies 0.52 ; $1.45 ; 2.50 ; 3.52 \mathrm{~Hz}$, clearly confirm the natural frequencies obtained by numerical way in the frequency range $0.5-5.0 \mathrm{~Hz}$. Natural frequencies in the frequency range higher than $5.0 \mathrm{~Hz}$ were not able to excite by passing the vehicle.

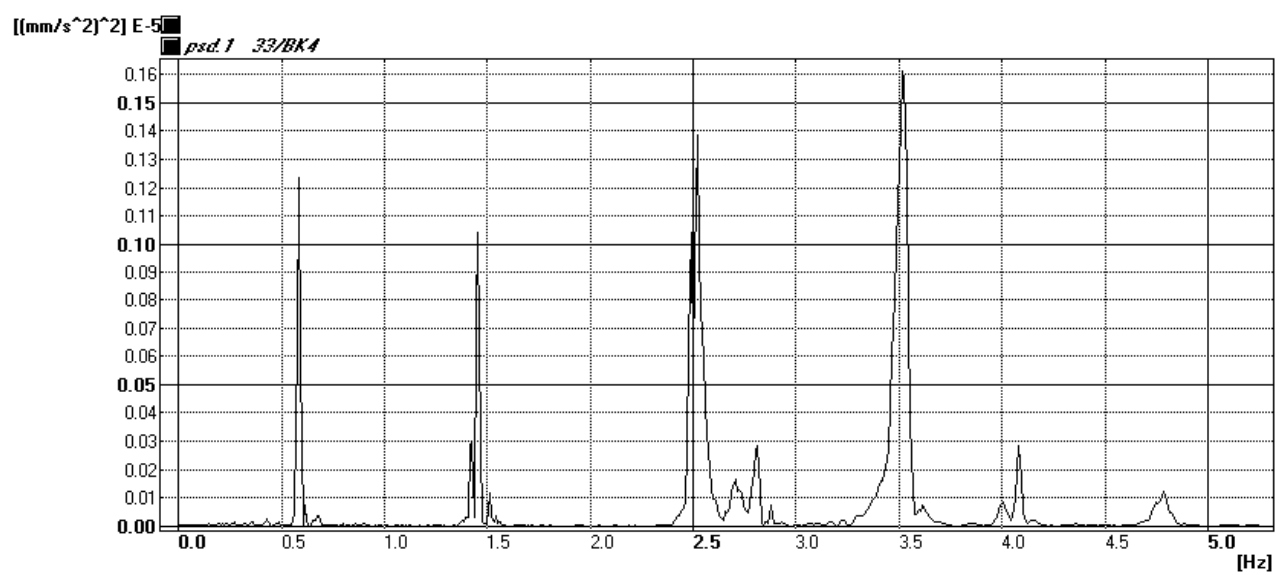

Fig. 9. The peaks in PSD correspond to the frequencies $0.52 ; 1.45 ; 2.50 ; 3.52 \mathrm{~Hz}$.

\section{Conclusions}

The SNP Bridge over the Danube in Bratislava is an important steel cable-stayed bridge. All its dynamic characteristics are periodically monitored. After reconstruction in the year 2004 the studying loading test of the structure was carried out. It was found out during this loading test that the dilatation system on the Petržalka side is not in order and it acts as a generator of vibration. Passage of vehicle along this dilatation system evocates enormously the vibration of the end span, see Fig. 4 and Fig. 5. Such vibration negatively influences the fatigue processes in this part of the structure. Dynamic coefficients of deflections for this part of the structure are very high. Maximal value of dynamic coefficient for smooth runs is $\delta_{\text {obs, } \max }=1.96$ and for runs over norm plank is $\delta_{\text {obs, } \max }=2.27$. As we can see form the Fig. 3 the zone of critical speeds of vehicles is from $30 \mathrm{~km} / \mathrm{h}$ to $40 \mathrm{~km} / \mathrm{h}$, approximately 37 $\mathrm{km} / \mathrm{h}$. On the basis of experimental measurements the failure on the dilatation unit was detected and the dilatation unit was renovated. The system of fixation of bearing cables causes that the bridge is predisposed to rotational movements. This fact is clearly documented on the Fig. 6, where comparison of time processes of vibration from the sensors B1 and B2 situated on left and right side of the structure is shown. Frequency analysis of obtained records confirms all the frequencies obtained by numerical way in the year 1999. On the basis of this result we can say that the bearing system of the bridge does not show any defects.

\section{Reference}

1. J. Melcer, Studying loading test of the SNP Bridge over the Danube in Bratislava carried out in August 7/8, 2004 (Žilina, 2004)

2. J. Melcer, Dynamic calculation of highway bridges (EDIS ŽU, Žilina, 1997) 